\title{
Morphological and Molecular Diversity in Turkish Sesame Germplasm and Core Set Selection
}

\author{
Anne Frary, Pelin Tekin, Ibrahim Celik, Seymus Furat, Bulent Uzun, and Sami Doganlar*
}

\begin{abstract}
The conservation of plant germplasm is essential to ensure future breeding gains and crop bio-diversity. To be truly useful, such germplasm must be characterized for morphological traits and genetic diversity. In this work, agro-morphological diversity was assessed in 137 Turkish sesame (Sesamum indicum L.) genotypes (129 accessions and eight cultivars) by examination of eight qualitative and nine quantitative traits. As expected, morphological variability in the cultivars was low with broader diversity present in sesame accessions. However, some accessions were identified with interesting features, such as increased number of capsules and seed yield, which could be employed in future cultivar development. The sesame genotypes were analyzed for molecular genetic diversity with 140 amplified fragment length polymorphism (AFLP) loci. The results indicated a relatively low level of variability with an average dissimilarity value of 0.33 for all genotypes. Population structure was also examined and indicated that the material fell into two subpopulations. As most of the accessions (82\%) were obtained from the U.S. Department of Agriculture (USDA) and are not yet housed in the Turkish national sesame germplasm collection, the data were used to identify a core set of 22 accessions that should be preserved in Turkey. The importance of using both molecular and morphological data for core selection is highlighted with a focus on germplasm preservation and breeding.
\end{abstract}

A. Frary, P. Tekin, I. Celik and S. Doganlar, Dep. of Molecular Biology and Genetics, Izmir Institute of Technology, Urla, Izmir Turkey; S. Furat,West Mediterranean Agricultural Research Institute, Aksu, Antalya Turkey; and B. Uzun, Department of Field Crops, Akdeniz University, Antalya Turkey. Received 20 Jan. 2014. ^Corresponding author (samidoganlar@iyte.edu.tr).

Abbreviations: AARI, Aegean Agricultural Research Institute; AFLP, amplified fragment length polymorphism; BATEM, West Mediterranean Agricultural Research Institute; PCA, principal component analysis; PCoA, principal coordinate analysis; USDA, United States Department of Agriculture.

Cesame is an important oil seed crop adapted to tropical and $\checkmark$ subtropical areas. Sesame is not an ideal crop: it is susceptible to drought, diseases, insect pests and pathogens; it has non-synchronous maturity; an indeterminate growth habit; seed shattering; profuse branching; and low yield and harvest index (Ashri, 1998; Bedigian, 2003). Nonetheless, sesame is widely cultivated especially in undeveloped and developing areas that depend on rain-fed agriculture, such as east Asia and Africa. Myanmar leads in sesame production with 620,000 metric tonnes (Mt), 15\% of the world harvest, produced in 2012 (Faostat, 2012, accessed 16 Dec. 2013). India, China, Tanzania, and Ethiopia are also major producers of sesame and account for an additional $46 \%$ of production. Sesame is mainly used for its seed and high quality seed oil but its leaves are also edible and can be important for food security during difficult times (Bedigian 2003). Among oil crops, sesame seed has one of the highest oil contents with 50 to $60 \%$ oil (Ashri, 1998). This oil is rich in polyunsaturated fatty acids; oleic and linoeic acids; and antioxidants such as sesamin, sesamolin, sesamol, sesamolinol, and

\footnotetext{
Published in Crop Sci. 55:702-711 (2015).

doi: 10.2135/cropsci2014.01.0048

C Crop Science Society of America | 5585 Guilford Rd., Madison, WI 53711 USA

All rights reserved. No part of this periodical may be reproduced or transmitted in any form or by any means, electronic or mechanical, including photocopying, recording, or any information storage and retrieval system, without permission in writing from the publisher. Permission for printing and for reprinting the material contained herein has been obtained by the publisher.
} 
squalene (Weiss, 1983; Mohamed and Awatif, 1998) which increase the stability of sesame oil (Budowski and Markley, 1951). Sesame seed oil is reported to have diverse health benefits including reducing cholesterol levels and lowering blood pressure (Noguchi et al., 2004; Sankar et al., 2005). Compounds present in sesame are also reported to have antimicrobial effects (Costa et al., 2007; Laurentin, 2007).

Sesame has a diploid chromosome number of $2 n=26$ and an annual growth habit. It is autogamous and populations are usually comprised of homozygous individuals. However, despite its amenability to genetic studies and its economic importance in some parts of the world, sesame is an ignored and under-utilized crop (Bedigian, 2003). The main breeding goal for sesame is increased yield which, according to Baydar (2005), can be achieved with plants that are branching and have increased numbers of capsules per axil and carpels per capsule. Determinate and nonshattering types are also of interest for their ease of harvest (Ashri, 1998). Breeding strategies in the crop include selection from germplasm as well as mutagenesis (e.g., Pathirana, 1992; Cagirgan, 2006) and hybridization programs (e.g., Murty, 1975; Gaikwad et al., 2009).

As in any crop, improvement of sesame requires knowledge of the genetic diversity of its germplasm collections as well as genetic relationships among accessions. Many studies have characterized morphological diversity of sesame germplasm (e.g., Bedigian et al., 1986; Bisht et al., 1998; Furat and Uzun, 2010). However, although molecular markers have been used extensively to characterize diversity in other crops, sesame research has lagged behind with most of the work done in the past decade. In one such study, Laurentin and colleagues (Laurentin and Karlovsky, 2006; Laurentin et al., 2008) studied genetic and metabolic diversity in sesame accessions using AFLP. AFLP was also used to study molecular and morphological diversity in 96 sesame accessions from throughout the world (Ali, 2007). More recently, sesame-specific markers including genic and genomic simple sequence repeats (SSRs) (Dixit et al., 2005; Wei et al., 2008; Cho et al., 2011; Wei et al., 2011; Zhang et al., 2012a) have been developed for sesame and used to study diversity in worldwide accessions.

The overall goals of this work were to examine the morphological and molecular diversity of Turkish sesame accessions and to use this information to select a core set for inclusion in the national collection. Most of the sesame material (106 accessions, 82\%) represented Turkish accessions collected by or submitted to the USDA in the mid-20th century. Many of these accessions were collected in the late 1940s by J.R. Harlan, the polymath who refined Vavilov's concept of centers of origin (Hymowitz, 1990). Although some of the material has been morphologically characterized in previous work based in the United States (Bedigian et al., 1986; Morris, 2009); to our knowledge, these genotypes have not been assessed under
Turkish conditions. Eight Turkish cultivars and 23 accessions collected by the Aegean Agricultural Research Institute (AARI) since the 1970s were also included for comparison. Qualitative and quantitative morphological traits were studied to assess the usefulness of the germplasm for improvement of sesame cultivars while molecular diversity was determined with AFLP markers. AFLP markers were selected because they are highly polymorphic, reproducible, and do not require any sequence information.

\section{MATERIALS AND METHODS Plant Material and Growth Conditions}

A total of 106 accessions were obtained from the USDA Plant Genetic Resources Conservation Unit, Griffin, GA. These accessions represent a majority (70\%) of the Turkish sesame germplasm held by the USDA. In addition, 23 accessions and five cultivars were obtained from AARI, Menemen, Izmir, Turkey. Three additional cultivars were obtained from West Mediterranean Agricultural Research Institute (BATEM), Antalya, Turkey. Three of the eight cultivars were landraces registered by BATEM: Golmarmara (abbreviated as $\mathrm{G}$ in figures), Muganli-57 (M), and Ozberk (Oz). The other cultivars were released by AARI: Cumhuriyet 99 (C), Kepsut 99 (K), Orhangazi 99 (Or), Osmanli 99 (Os), and Tan 99 (T). Two accessions from Korea and Africa were contributed by Dr. Petr Karlovsky, University of Gottingen, Gottingen, Germany. All accessions and their origins are listed in Supplemental Table 1. The Aegean region was the source of the most accessions (41), followed by the Marmara and Mediterreanean regions (32 accessions each) (Supplemental Fig. 1). Relatively few accessions were collected in East Anatolia (10), Southeast Anatolia (6), Central Anatolia (3), and the Black Sea region (1). The remaining four accessions were from unknown locations in Turkey.

For morphological analysis, plants were grown at BATEM during the 2009 and 2010 growing seasons. This site is located at $36^{\circ} 52^{\prime} \mathrm{N}, 30^{\circ} 50^{\prime} \mathrm{E}$, and approximately $15 \mathrm{~m}$ above sea level. It has average annual precipitation of $1060 \mathrm{~mm}$ and average annual temperature of $18^{\circ} \mathrm{C}$. The experimental field is characterized by silty clay loam soil with $\mathrm{pH}$ 7.8. The accessions were grown in $5 \mathrm{~m}$ long, one-row plots in 2009 and $5 \mathrm{~m}$ long, two-row plots in 2010 with a row to row spacing of $70 \mathrm{~cm}$ and plant to plant spacing of $10 \mathrm{~cm}$. The experimental design was an augmented block in both years with four replications of the controls: Golmarmara,Muganli-57, Ozberk, and Tan 99. At sowing, $60 \mathrm{~kg} / \mathrm{ha} \mathrm{N}, \mathrm{P}$, and $\mathrm{K}$ composite fertilizer was applied. For molecular analysis, 10 seeds from each accession were planted and grown in soil containing peat moss, perlite, and natural fertilizer. Plants were grown in the growth chamber at 23 to $25^{\circ} \mathrm{C}, 18 / 6 \mathrm{~h}$ photoperiod and approximately $35 \%$ humidity at Izmir Institute of Technology.

\section{Morphological Analysis}

A total of 17 qualitative and quantitative characters (IPGRI and NBPGR, 2004) were recorded for each plot. There was no within plot variation for these traits indicating that the accessions were homogeneous. The qualitative characters were branching habit, stem hairiness, leaf hairiness, number of 
Table 1. Qualitative morphological traits measured in the sesame accessions. Means and percentages of individuals belonging to each trait class are given for accessions (acc) and cultivars (cv).

\begin{tabular}{|c|c|c|c|c|c|}
\hline \multirow[b]{2}{*}{ Trait } & \multicolumn{2}{|c|}{ Mean \pm SE } & \multirow{2}{*}{$\begin{array}{c}\text { Class: } \\
\text { description }\end{array}$} & \multicolumn{2}{|c|}{ Percentage } \\
\hline & Acc & Cv & & Acc & Cv \\
\hline & & & & - & - \\
\hline \multirow{2}{*}{$\begin{array}{l}\text { Plant growth } \\
\text { type }\end{array}$} & $1.0 \pm 0$ & $1.0 \pm 0$ & 1: indeterminate & 100 & 100 \\
\hline & & & 2: determinate & 0 & 0 \\
\hline \multirow{2}{*}{$\begin{array}{l}\text { Stem } \\
\text { branching }\end{array}$} & $1.0 \pm 0$ & $1.0 \pm 0$ & 0: absent & 0 & 0 \\
\hline & & & 1: present & 100 & 100 \\
\hline \multirow[t]{4}{*}{$\begin{array}{l}\text { Stem } \\
\text { hairiness }\end{array}$} & $3.2 \pm 0.1$ & $3.2 \pm 0.2$ & $\begin{array}{l}0: \text { glabrous } \\
\text { (none) }\end{array}$ & 0 & 0 \\
\hline & & & 3: sparse & 94.6 & 87.5 \\
\hline & & & 5: medium & 1.6 & 12.5 \\
\hline & & & 7: profuse & 3.9 & 0 \\
\hline \multirow[t]{4}{*}{$\begin{array}{l}\text { Leaf } \\
\text { hairiness }\end{array}$} & $3.0 \pm 0.1$ & $3.2 \pm 0.2$ & $\begin{array}{l}0: \text { glabrous } \\
\text { (none) }\end{array}$ & 0 & 0 \\
\hline & & & 3: sparse & 97.7 & 87.5 \\
\hline & & & 5: medium & 2.3 & 12.5 \\
\hline & & & 7: profuse & 0 & 0 \\
\hline \multirow{2}{*}{$\begin{array}{l}\text { Number of } \\
\text { flowers per } \\
\text { leaf axil }\end{array}$} & $1.0 \pm 0.1$ & $1.0 \pm 0$ & 1: one & 96.9 & 100 \\
\hline & & & 2: more than one & 3.1 & 0 \\
\hline \multirow{2}{*}{$\begin{array}{l}\text { Number of } \\
\text { carpels per } \\
\text { capsule }\end{array}$} & $1.0 \pm 0.1$ & $1.0 \pm 0$ & 1: bicarpellate & 99.2 & 100 \\
\hline & & & 2: quadricarpellate & 0.8 & 0 \\
\hline \multirow[t]{4}{*}{$\begin{array}{l}\text { Capsule } \\
\text { hairiness }\end{array}$} & $3.2 \pm 0.1$ & $3.5 \pm 0.5$ & $\begin{array}{l}\text { 0: glabrous } \\
\text { (none) }\end{array}$ & 0 & 0 \\
\hline & & & 3: sparse & 93.8 & 87.5 \\
\hline & & & 5: medium & 3.9 & 0 \\
\hline & & & 7: profuse & 2.3 & 12.5 \\
\hline \multirow{3}{*}{$\begin{array}{l}\text { Caps. } \\
\text { dehiscence } \\
\text { at ripening }\end{array}$} & $3.0 \pm 0$ & $3.0 \pm 0$ & 1: nonshattering & 0 & 0 \\
\hline & & & 2: partially & 0 & 0 \\
\hline & & & 3: completely & 100 & 100 \\
\hline
\end{tabular}

flowers per leaf axil, plant growth type, number of carpel per capsule, capsule hairiness, and capsule dehiscence at ripening. The quantitative characters obtained on a plot basis were: days to flower initiation, days to 50\% flowering, 1000-seed weight (g), number of fruiting branches, and seed yield (kg/ha). Stem height to the first capsule $(\mathrm{cm})$, plant height $(\mathrm{cm})$, number of capsules per plant, and number of seeds per capsule were measured from three representative plants. Seed yield was recorded in grams per plot and then converted to kilograms per hectare.

Morphological data were analyzed using JMP 7.0 statistical program (SAS Institute, Cary, NC). Qualitative data were analyzed according to mean and percent distribution while quantitative data were analyzed by mean and coefficient of variation. Principal component analysis (PCA) was performed with quantitative data. Stepwise discriminant analysis of the morphological traits was done with location as the grouping variable.

\section{Amplified Fragment Length Polymorphism Analysis}

Genomic DNA was extracted from individual plants at the two- to four-leaf stage using a modified CTAB-DNA extraction protocol from Laurentin and Karlovsky (2006) and Abdellatef et al. (2008). The DNA was diluted to $100 \mathrm{ng} / \mu \mathrm{L}$ in Tris-EDTA (TE) buffer for each sample, bulked for 10 plants per accession and stored at $-20^{\circ} \mathrm{C}$ until use. The AFLP Core Reagent and AFLP Starter Primer Kits from Invitrogen (Carlsbad, CA) were used according to the manufacturer's protocol. Selective amplification was performed with five primer combinations: E-ACA + M-CAG, E-ACA + M-CAC, E-ACA + M-CAA, E-ACA + M-CTC and E-ACA + M-CAT. A CEQ8800 Sequencer (Beckman-Coulter, Fullerton, CA) was used for fragment separation. Therefore, AFLP primers were labeled with blue fluorescent dye and amplification products were diluted 1:10 in sample loading solution (SLS) with $0.5 \mu \mathrm{L}$ size standard 600. The default Frag 4 separation method was used: capillary temperature $50^{\circ} \mathrm{C}$, denaturation temperature $90^{\circ} \mathrm{C}$ for $120 \mathrm{~s}$, injection voltage $2.0 \mathrm{kV}$ for $30 \mathrm{~s}$, and separation voltage of $4.8 \mathrm{kV}$ for $60.0 \mathrm{~min}$.

The AFLP fragments were scored as present (1) or absent (0). These data were analyzed for population structure using the computer program Structure (Pritchard et al., 2000) which assigns accessions to subpopulations. Models with 1 to $20(\mathrm{~K}=$ 1-20) subpopulations were tested after 50,000 burn-in cycles. Each model was tested 20 times with 100,000 iterations per K. The Structure Harvester program (Earl and Von Holt, 2012) was used to calculate the values of $\Delta \mathrm{K}$ using the posterior probabilities of the data for each model. The highest $\Delta \mathrm{K}$ was used to select the model that best described the data. A threshold of $\geq 0.70$ inferred ancestry was used to assign accessions to subpopulation clusters. Accessions which did not meet this threshold value were considered to be admixed.

Molecular genetic diversity of the sesame accessions was also determined by calculating pairwise genetic dissimilarity values using Jaccard's coefficient as implemented in the DARwin 5 computer program (Perrier and Jacquemoud-Collet, 2006). DARwin was also used to construct an unweighted neighbor-joining dendrogram of the accessions and for principal coordinate analysis (PCoA).

\section{Core Set Selection}

Core sets of USDA accessions were selected using the AFLP data, the morphological data and the combined data sets. Set selection was performed with PowerCore 1.0 software (Kim et al., 2007) which uses the M strategy and a modified heuristic algorithm.

\section{RESULTS AND DISCUSSION Morphological Trait Diversity}

The 129 sesame accessions and eight cultivars were assessed for eight qualitative (Table 1) and nine quantitative (Table 2) morphological traits. Germplasm accessions and cultivars were analyzed separately to assess the breeding potential of the germplasm. No variation was observed for plant growth type, stem branching, and capsule dehiscence at ripening; all plants were indeterminate, branched, and completely shattering (Table 1). Limited variation was observed for hairiness. More than 93\% of the accessions had sparse stem, leaf, and capsule hairiness. Only one cultivar, Orhangazi 99, had moderate stem and leaf hairiness with profuse capsule hairiness. As might be expected, hairiness of different organs was correlated. However, stem hairiness showed only weak correlations to capsule and leaf hairiness 
Table 2. Quantitative morphological traits for the sesame accessions. Means and CV are given for accessions and cultivars.

\begin{tabular}{|c|c|c|c|c|c|c|}
\hline \multirow[b]{2}{*}{ Trait } & \multicolumn{3}{|c|}{ Accessions } & \multicolumn{3}{|c|}{ Cultivars } \\
\hline & Mean \pm SE & CV & Range & Mean \pm SE & CV & Range \\
\hline & & $\%$ & & & $\%$ & \\
\hline Plant height, cm & $102.0 \pm 1.2$ & 13.3 & $65.0-138.0$ & $105.0 \pm 2.5$ & 6.8 & $95.1-114.8$ \\
\hline Number of primary branches & $3.7 \pm 0.1$ & 17.0 & $2.5-5.0$ & $3.5 \pm 0.3$ & 21.3 & $2.0-4.5$ \\
\hline Days to flower initiation & $35.4 \pm 0.3$ & 9.6 & $29.0-45.5$ & $34.8 \pm 0.8$ & 6.4 & $33.0-40.0$ \\
\hline Days to $50 \%$ flowering & $39.0 \pm 0.3$ & 9.2 & $32.0-49.0$ & $38.2 \pm 0.8$ & 6.0 & $35.0-42.5$ \\
\hline Distance to first capsule, $\mathrm{cm}$ & $36.1 \pm 0.6$ & 20.2 & $19.0-56.5$ & $39.0 \pm 1.6$ & 11.3 & $33.8-47.5$ \\
\hline Number of capsules per plant & $74.8 \pm 2.1$ & 32.1 & 21.0-197.0 & $64.4 \pm 5.0$ & 21.8 & $49.0-90.5$ \\
\hline Number of seeds per capsule & $66.2 \pm 1.4$ & 23.4 & $34.0-84.0$ & $75.4 \pm 0.8$ & 3.0 & $72.0-80.0$ \\
\hline 1000-seed weight, g & $3.0 \pm 0.04$ & 14.6 & $1.9-4.2$ & $3.4 \pm 0.1$ & 8.0 & $2.9-3.6$ \\
\hline Seed yield, $\mathrm{kg} \mathrm{ha}^{-1}$ & $271.8 \pm 7.2$ & 30.1 & $90.0-480.0$ & $286.2 \pm 12.9$ & 12.8 & $250.0-360.0$ \\
\hline
\end{tabular}

$(r=0.23-0.28$, respectively) while capsule and leaf hairiness were highly correlated $(r=0.87)$. Many studies have shown that trichomes can deter herbivory by physically interfering with feeding/movement or releasing toxic compounds (e.g., Kessler and Baldwin, 2002; Tian et al., 2012). In addition, trichomes protect leaves from excessive sunlight and may be related to resistance to wilting and drought tolerance in sesame and other species (reviewed in Bedigian, 2004). It is also reported that trichomes have important roles in the defense response to other types of biotic and abiotic stress and that they are rich in defenserelated proteins (Amme et al., 2005). Therefore, it might be interesting to use some of the accessions to increase hairiness in sesame cultivars. For example, PI179484 had medium stem and leaf hairiness and profuse capsule hairiness and could be tested for improved stress resistance.

The accessions showed wide variation in plant height with a $73 \mathrm{~cm}$ range while the cultivars only varied by 20 $\mathrm{cm}$ (Table 2). Approximately 10\% of the accessions were at least $10 \mathrm{~cm}$ shorter than the shortest cultivars (Ozberk and Muganli-57, $95 \mathrm{~cm}$ ). Shorter accessions may be more resistant to lodging than taller ones. However, care must be taken that yield is not sacrificed for lodging resistance as was observed with determinate sesame mutants (Uzun and Cagirgan, 2006). In our work, accession PI182295 was much shorter than average (only $65 \mathrm{~cm}$ ) but had severe reductions in numbers of capsules (21 per plant). Overall, however, there was no significant correlation between plant height and yield. Thus, some accessions combined shortness with capsule and seed numbers that were comparable or better than the cultivar averages, indicating their usefulness in breeding programs.

All accessions and cultivars were branching with an average of 3.5 primary branches per plant. Similar variation in branch number was observed in both accessions and cultivars with two to five branches per plant. Branch number is often associated with yield (Kang et al., 1984; Lee et al., 1984; Baydar, 2005). Indeed, number of branches showed a moderate correlation $(r=0.43)$ to number of capsules, but no significant correlation to seed yield.
Time to flower initiation averaged $35 \mathrm{~d}$ for both accessions and cultivars with 50\% flowering occurring, on average, $4 \mathrm{~d}$ after initiation in both sets of material. The accessions, however, showed a wider range in flowering time traits with material that flowered $4 \mathrm{~d}$ earlier than the earliest cultivars (Kepsut 99 and Muganli-57), as well as accessions that flowered up to $5 \mathrm{~d}$ later than the latest cultivar (Osmanli 99). Approximately $20 \%$ of the germplasm accessions initiated flowering earlier than the cultivars indicating that they could be a good source of alleles for earliness. Similar variation for earliness and lateness were observed for $50 \%$ flowering. As expected, days to flower initiation and 50\% flowering were highly correlated $(r=0.88)$. All cultivars and most accessions had only one flower per leaf axil. Only four accessions had more than one flower per leaf axil.

Average distance to first capsule (stem height to first capsule) was similar for both accessions and cultivars with the accessions having more variation $(\mathrm{CV}=20$ vs. $11 \%)$. As might be expected, distance to first capsule was positively correlated with plant height $(r=0.52)$. Number of capsules per plant had much wider variation in the accessions $(21-197, \mathrm{CV}=32 \%)$ than in the cultivars (49-90, $\mathrm{CV}=21 \%$ ). Taller plants tended to produce more capsules $(r=0.35)$ but, as previously mentioned, there was no correlation between plant height and seed yield. There was also no correlation between capsule number and seed yield. The accessions were either bicarpellate or quadricarpellate, however, all cultivars were bicarpellate. Contrary to the findings of Baydar (2005), number of carpels showed no association with seed number per plant. This was also observed by Yol and Uzun (2012) who postulated that photosynthesis rather than carpel number was the limiting factor for seed yield. Number of seeds per capsule was variable in the accessions $(\mathrm{CV}=23 \%)$ with as many as 84 seeds per capsule. The cultivars had much less variation for this trait $(\mathrm{CV}=3 \%)$ with an average of 75 seeds per capsule. Kepsut 99 had the most seeds per capsule, 80 . Thirteen accessions (10\%) had as many or more seeds than Kepsut 99 indicating that they contained useful 
Table 3. Principal component analysis of quantitative traits. Eigen values are given for the first three principal component (PC) axes.

\begin{tabular}{lrrr}
\hline \multicolumn{1}{c}{ Trait } & PC1 & \multicolumn{1}{c}{ PC2 } & \multicolumn{1}{c}{ PC3 } \\
\hline Plant height & 0.418 & 0.014 & 0.458 \\
Number of primary branches & 0.206 & -0.470 & 0.202 \\
Days to flower initiation & 0.508 & 0.229 & -0.359 \\
Days to 50\% flowering & 0.527 & 0.188 & -0.296 \\
Distance to first capsule & 0.381 & 0.263 & 0.336 \\
Number of capsules per plant & 0.236 & -0.590 & 0.222 \\
Number of seeds per capsule & -0.042 & 0.353 & 0.555 \\
1000-seed weight & -0.197 & 0.381 & 0.213 \\
Seed yield & -0.076 & -0.060 & 0.132 \\
\hline
\end{tabular}

alleles for improvement of this trait. Thousand seed weight was slightly higher for the cultivars ( $3.4 \mathrm{~g})$ than for the accessions (3.0 g). Orhangazi 99 and Muganli-57 had the heaviest seeds with 1000-seed weights of approximately $3.6 \mathrm{~g}$. Average seed yield of the cultivars $\left(286 \mathrm{~kg} \mathrm{ha}^{-1}\right)$ was only slightly higher than that for the accessions $(272 \mathrm{~kg}$ $\mathrm{ha}^{-1}$ ). Osmanli 99 had the highest seed yield and produced $360 \mathrm{~kg} \mathrm{ha}^{-1}$. Nearly $13 \%$ of the accessions had higher seed yields than Osmanli 99 with one accession (PI 238426) producing $480 \mathrm{~kg} \mathrm{ha}^{-1}$. Interestingly, this accession was one of only four accessions which produced more than one flower per axil. Based on the morphological trait analysis, it was apparent that some accessions contain useful variation for improvement of seed traits.

Principal component analysis (PCA) of the quantitative traits indicated that the first three Eigen vectors explained $59.5 \%$ of the morphological variation in the cultivars and accessions. The first Eigen vector (PC1) accounted for $27.8 \%$ of the variation with high positive correlations to flowering time and height traits (Table 3). PC2 explained $17.2 \%$ of the variation with the highest positive correlations to number of seeds per capsules and 100 seed weight and a strong negative correlation to number of primary branches. PC3 (14.5\% of variation) was most positively correlated to plant height and seed number and negatively correlated to flowering time traits. The two-dimensional PCA plot of the data showed that the accessions had wider variation for the morphological traits than the cultivars (Fig. 1). The accessions collected by AARI since the 1970s also had less variation than those collected by the USDA in the 1940s and 1950s. This was evident as most of the AARI accessions were located in the upper left quadrant of the PCA. These results indicate reduced genetic diversity in natural populations over time or may simply be the result of the smaller sample size used for the AARI germplasm (23 vs. 106 accessions). Overall, the results from the morphological trait analyses indicate that at least some of the USDA accessions should be incorporated into the Turkish national sesame collection as they will provide morphological variation and promise for cultivar yield improvement.
Stepwise discriminant analysis was performed using collection location as a grouping variable and all morphological traits as independents. Only plant height, days to flower initiation, and number of seeds per capsule made significant contributions to the multivariate discrimination of the eight locations. These traits had only moderate correlation $(r=0.54-0.62)$ with location. Further analysis was done for the three collection locations with large numbers of samples: the Marmara (32 accessions), Mediterranean (32), and Aegean (41) regions. Tukey-Kramer honest significant difference (HSD) analysis $(p \leq 0.05)$ indicated that, on average, the Marmara accessions were significantly shorter than those from the other two regions with a mean height of $96( \pm 2.2) \mathrm{cm}$. The Mediterranean accessions were significantly taller than both Aegean and Marmara accessions with a mean height of $108( \pm 2.4) \mathrm{cm}$. Flowering time (days to flower initiation) was significantly shorter for the Marmara accessions ( $34.3 \pm 0.5 \mathrm{~d}$ ) as compared to the Mediterranean ones $(36.4 \pm 0.6 \mathrm{~d})$ while the Aegean accessions had intermediate flowering time. Number of seeds per capsule showed a similar trend with the fewest average number of seeds for the Marmara accessions (58.1 \pm 3.1 seeds) and the most for the Mediterranean ones (68.9 \pm 2.2 seeds). This difference was also statistically significant. These correlations may reflect adaptation to the climatic conditions in these three locations. The Marmara region is the coolest with average temperatures reaching $14^{\circ} \mathrm{C}$ year round and an average of $27^{\circ} \mathrm{C}$ in summer (Sensoy et al., 2008). The Mediterranean region is the hottest and sunniest of the three locations with average temperatures up to $20^{\circ} \mathrm{C}$ year round and an average of $29^{\circ} \mathrm{C}$ in summer. Thus, the shorter, faster flowering sesame accessions were collected in the cooler Marmara climate while taller, later flowering, and higher yielding accessions were found in the hotter Mediterranean regions.

\section{Molecular Genetic Diversity}

The 129 Turkish sesame accessions, eight cultivars, and two foreign accessions (Africa and Korea) were examined for AFLPs using five primer combinations. A total of 148 polymorphic fragments were obtained with the most fragments, 46, for combination E-ACA + M-CAT. The fewest fragments, 14, were obtained for combination E-ACA + M-CAG. Alleles that were difficult to score were eliminated from the dataset resulting in 140 fragments which were used for population structure and diversity analyses.

Population structure analysis suggested that the accessions clustered into two subpopulations ( $\mathrm{K}=2 ; 0.70$ identity threshold) with 25 accessions in cluster A, 86 accessions in cluster B and 28 admixed accessions (Supplemental Table 1, Fig. 2). Cluster A did not contain any cultivars while cluster B contained six Turkish cultivars and the African sesame accession. The admixed accessions included two cultivars, Golmarmara and Muganli-57, and the Korean 


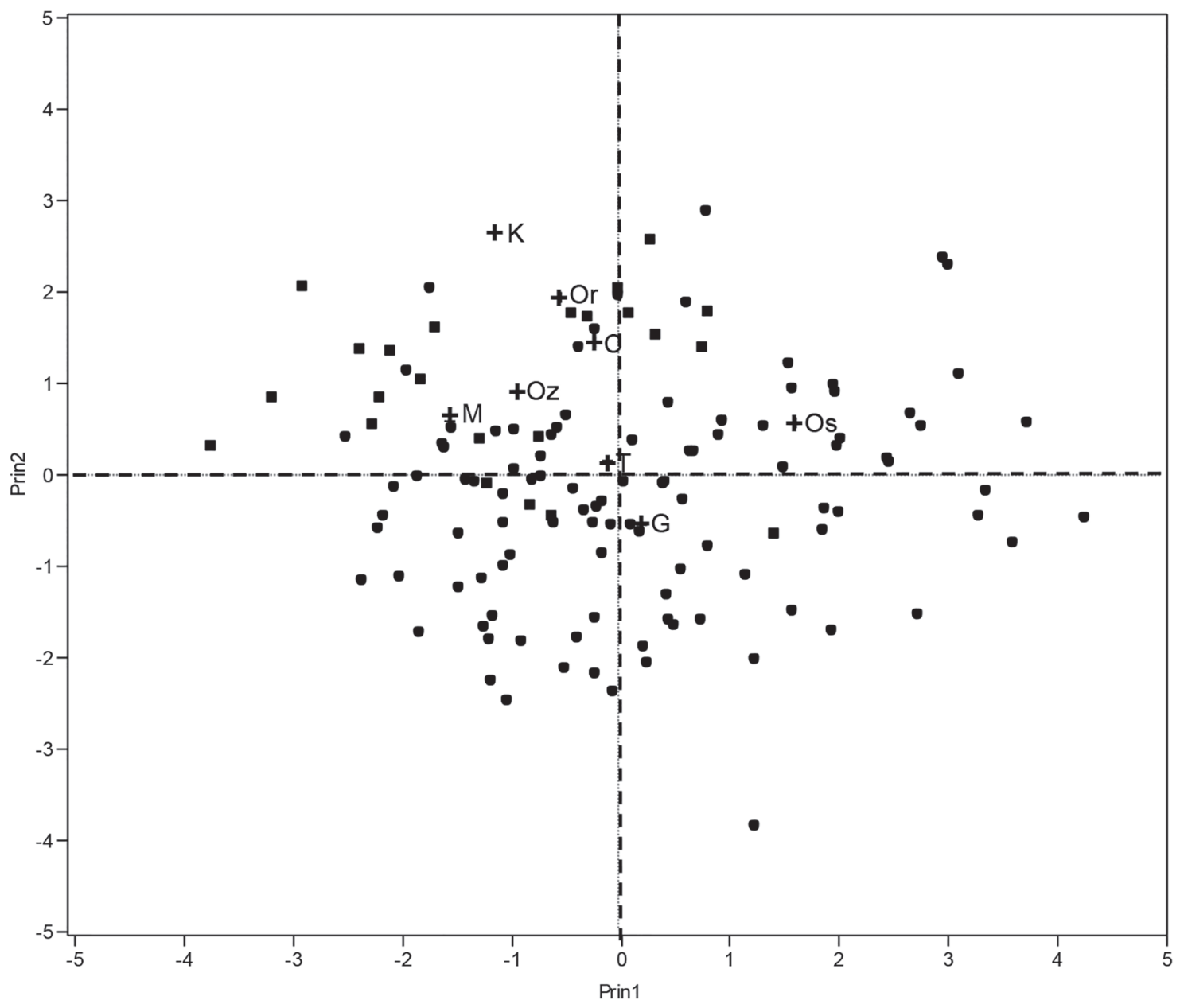

Figure 1. Two-dimensional principal component analysis (PCA) plot for quantitative morphological data. Plus signs indicate cultivars which are abbreviated as described in Materials and Methods. Squares indicate Aegean Agricultural Research Institute (AARI) accessions while circles indicate USDA accessions.

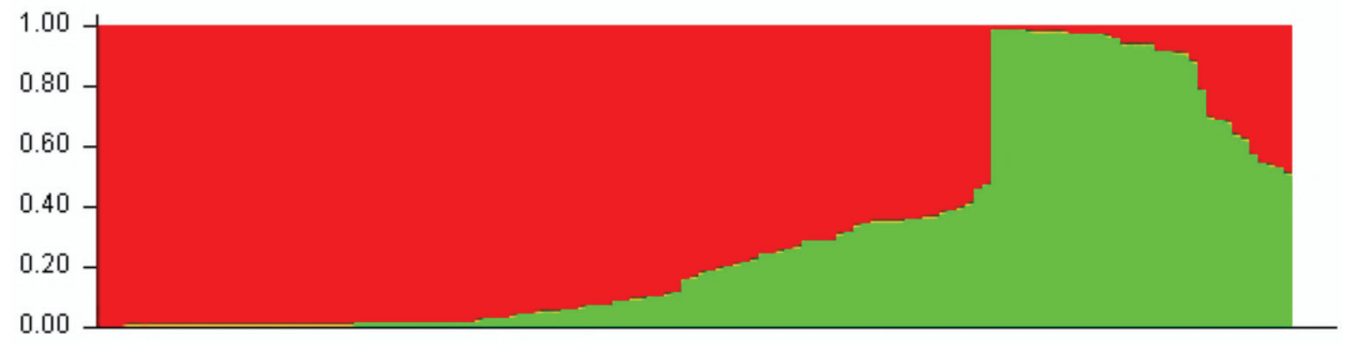

Figure 2. Bar plot showing genetic structure of sesame accessions with $K=2$. Each accession is represented by a vertical bar which is partitioned according to estimated membership in the two clusters. Cluster A fraction is shown in green and cluster B fraction in red.

sesame accession. Clustering based on population structure showed no relationship to collection location.

Diversity analysis of the molecular data using Jaccard's dissimilarity index indicated that pairwise dissimilarity among the accessions varied from 0.05 to 0.63 with a mean of 0.33 . The neighbor-joining dendrogram of the accessions had a very good fit with the dissimilarity matrix (Mantel test $r=0.95$ ) and showed that all of the cluster A accessions formed a single group which also included two admixed accessions (data not shown). Two-dimensional
PCoA clearly showed that cluster A was distinct from cluster B while the admixed accessions occupied the space between these two clusters (Fig. 3). Maximum dissimilarities for clusters A and B were 0.55 and 0.47 , respectively, while the mean dissimilarities for these clusters were 0.36 and 0.25 , respectively. Thus, genetic diversity was higher in cluster A than in cluster B. The admixed accessions had maximum and mean dissimilarity values $(0.56$ and 0.34 , respectively) which were similar to those for cluster A. 


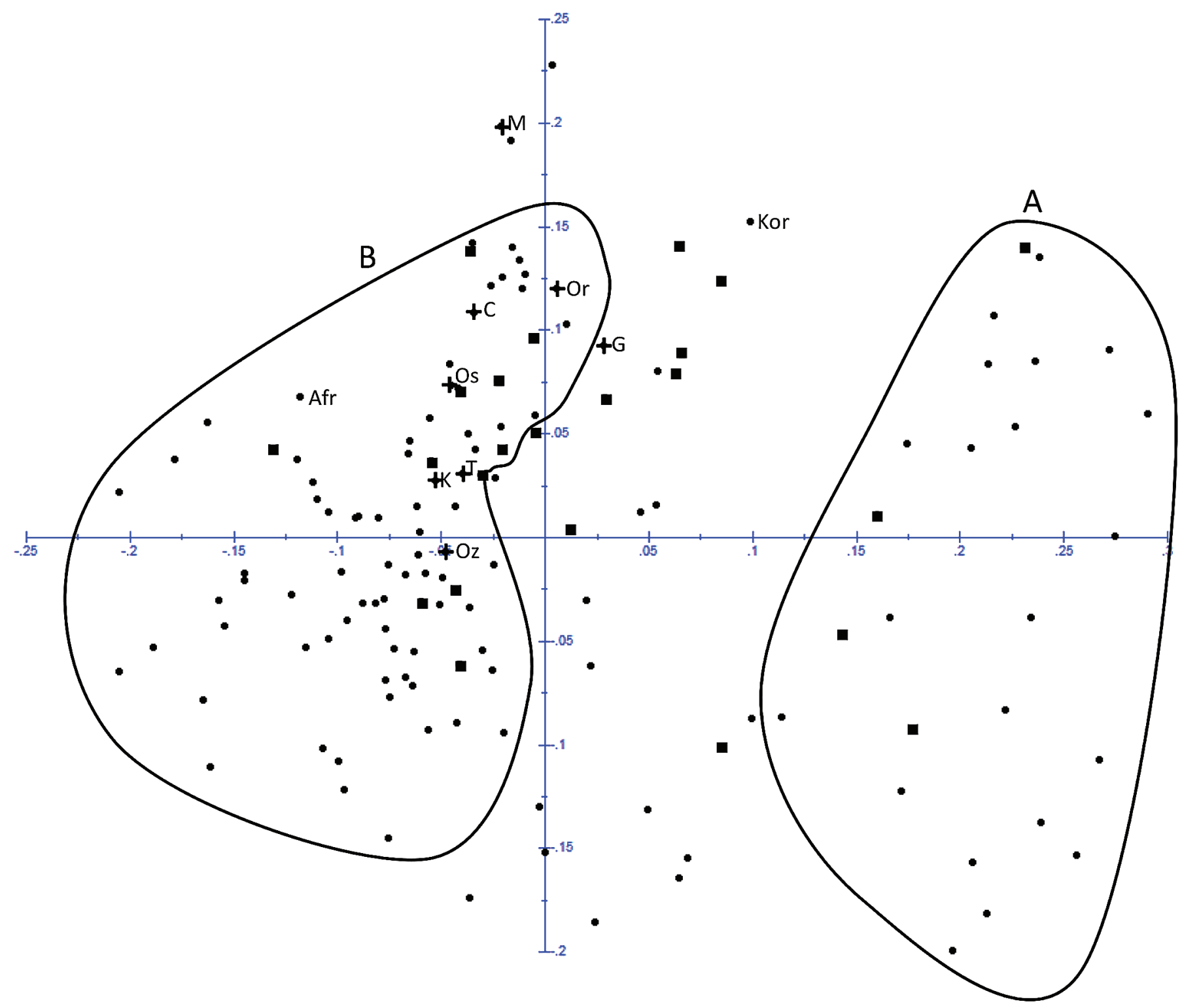

Figure 3. Two-dimensional principal coordinate analysis (PCOA) of sesame accessions using amplified fragment length polymorphism (AFLP) data. Eigen values for the first two principal components were 15.8 and 9.1. Plus signs indicate cultivars which are abbreviated as described in Materials and Methods. Squares indicate Aegean Agricultural Research Institute (AARI) accessions while circles indicate USDA accessions. Clusters A and B (identified by population structure analysis) are circled and labelled. Other accessions are admixed.

When examined by source, it was seen that the USDA and AARI accessions had similar levels of diversity with identical mean dissimilarity values, 0.32. Accessions from USDA and AARI showed different distributions according to cluster analysis performed by Structure. Most (65\%) of the USDA accessions were in cluster B with the remainder split between cluster A (20\%) and the admixed group (15\%). In contrast, the AARI accessions were nearly equally divided between cluster B (43\%) and the admixed group (39\%) with a minority (17\%) in cluster A. These differences in distribution may reflect a trend toward more admixing over time. Thus, the accessions collected in the 1940s and 1950s by the USDA showed little admixing (only 15\%), while a sizable proportion $(39 \%)$ of those collected since the 1970s by AARI, were admixtures of clusters A and B. These results suggest greater interbreeding between clusters over time. It is difficult to determine if this interbreeding was due to natural cross-pollination or farmer-directed crosses. However, it is interesting to note that two of the three landrace cultivars used in this study, Golmarmara and Muganli-57, were admixed which suggests that farmers may have been involved in the admixing process.

\section{Selection of Core Sets}

To prioritize the USDA accessions that should be included in the Turkish national germplasm collection, core sets of USDA accessions were determined. These sets were selected using three types of data: AFLP, morphological, 
Table 4. Pedigree numbers of core sets selected using amplified fragment length polymorphism (AFLP) (A-core), morphological traits (M-core), or both (A\&M-core). Number of accessions in each core is given in parenthesis at the top of column. Cluster assignment is given in parenthesis after pedigree number.

\begin{tabular}{|c|c|c|}
\hline A-core (11) & M-core (17) & A\&M-core (22) \\
\hline PI $167248(B)^{\dagger}$ & PI 170715 (B) & PI 167248 (B) \\
\hline PI 170715 (B) & PI $170730(B)$ & PI 170715 (B) \\
\hline PI 177072 (A) & PI 170749 (A) & PI 170749 (A) \\
\hline PI 238428 (ad) & PI 173101 (B) & PI $177541(\mathrm{~A})$ \\
\hline $\mathrm{Pl} 238431(\mathrm{~A})$ & PI $177541(\mathrm{~A})$ & PI 179034 (B) \\
\hline PI 238440 (B) & PI 179034 (B) & Pl 179484 (ad) \\
\hline PI 238463 (A) & PI 179484 (ad) & PI 179490 (A) \\
\hline PI 238474 (B) & PI $182295(A)$ & PI 182295 (A) \\
\hline PI 238481 (B) & PI 238417 (ad) & PI 238426 (B) \\
\hline PI 238487 (B) & PI 238428 (ad) & PI $238428(a d)$ \\
\hline \multirow[t]{12}{*}{ PI 240844 (B) } & PI 238441 (B) & Pl 238434 (ad) \\
\hline & PI 238442 (B) & PI 238441 (B) \\
\hline & PI 238487 (B) & PI 238450 (B) \\
\hline & PI 240844 (B) & PI 238455 (B) \\
\hline & PI 240846 (B) & PI $238462(A)$ \\
\hline & PI 240850 (ad) & PI $238463(A)$ \\
\hline & PI $240856(A)$ & PI 238466 (B) \\
\hline & & PI 238469 (B) \\
\hline & & PI 238474 (B) \\
\hline & & PI 238481 (B) \\
\hline & & PI 238487 (B) \\
\hline & & PI 240844 (B) \\
\hline
\end{tabular}

† PI, Plant Introduction.

and the combined AFLP and morphological data. The molecular and morphological diversities of each core set were then compared with the original 106 USDA accessions and with the other core sets.

The core set selected using the AFLP data (A-Core) contained 11 individuals: three from cluster $\mathrm{A}$, seven from cluster B and 1 admixed accession (Table 4). A-Core showed no diversity for all but one qualitative morphological trait, number of flowers per leaf axil (Table 5). However, means and coefficients of variance for the quantitative traits showed similar levels of diversity as the entire set of USDA accessions (Table 6). A-Core had the same maximum molecular genetic dissimilarity as the entire set (0.63) while minimum and mean dissimilarities were higher with values of 0.24 and 0.43 , respectively (as compared to 0.05 and 0.32 for the entire USDA set). Overall, A-Core maintained the molecular genetic diversity of the entire collection with complete loss of variability for stem, leaf, and capsule hairiness, traits which had very low variability in the entire collection

The core set selected with the morphological data (M-Core) consisted of 17 accessions: four individuals from cluster A, nine from cluster B, and four admixed accessions (Table 4). Shannon diversity indices for the qualitative traits indicated that $\mathrm{M}$-Core was as diverse as the entire set
Table 5. Shannon diversity indices for the qualitative morphological traits for the 106 USDA accessions (acc) and each core set. Traits which were not variable in the sesame accessions are excluded.

\begin{tabular}{llccc}
\hline \multicolumn{1}{c}{ Trait } & $\begin{array}{c}\text { All USDA } \\
\text { acc }\end{array}$ & A-Core $^{\dagger}$ & M-Core & A\&M-Core \\
\hline Stem hairiness & 1.13 & 0 & 1.21 & 1.17 \\
Leaf hairiness & 1.06 & 0 & 1.10 & 1.14 \\
Number of flowers & 1.07 & 1.15 & 1.17 & 1.08 \\
Number of carpels & 0 & 0 & 0 & 0 \\
Capsule hairiness & 1.15 & 0 & 1.21 & 1.23 \\
\hline
\end{tabular}

† A-core, amplified fragment length polymorphism; M-core, morphological traits; A\&M-core, both amplified fragment length polymorphism and morphological traits.

for these traits (Table 5). The quantitative morphological traits also showed no significant loss of diversity (Table 6). Molecular dissimilarity for M-Core ranged from 0.09 to 0.61 while the mean dissimilarity was 0.37 . Thus, while some molecularly very similar accessions were maintained in M-Core, average molecular diversity was not adversely affected.

The third core set was selected using both molecular and morphological data (A\&M-Core). This set was the largest with 22 accessions: 6 from cluster A, 13 from cluster $\mathrm{B}$, and 3 admixed individuals (Table 4). Shannon diversity indices indicated that A\&M-Core was as diverse as the entire set for the qualitative traits (Table 5). Similar results were seen for the quantitative traits (Table 6). Molecular diversity was also maintained with genetic dissimilarity values ranging from 0.21 to 0.63 and a mean value of 0.41 .

Comparison of the three core sets indicates that, as expected, the use of both molecular and morphological data was the best method of core selection. The core selected with only molecular data lost qualitative morphological variation for trichome traits. This is significant as trichome traits seem to play significant roles in biotic and abiotic defense responses including insect resistance and drought tolerance (Bedigian, 2004; Amme et al., 2005). The core selected with only morphological data was problematic in that it retained accessions which were genotypically nearly identical. Such similarity limits molecular diversity in the germplasm and reduces the probability of finding new allelic combinations for sesame improvement. Thus, an ideal core set of 22 USDA accessions (21\% of the entire set) was selected using both molecular and morphological data. These accessions should be maintained in the Turkish national sesame germplasm repository.

To our knowledge, this is one of only two studies that have used both morphological and molecular diversity to select a core set of sesame accessions from a larger germplasm collection. The only other work was performed by Zhang et al. (2012b) who used 14 agronomic traits, SSR and sequence-related amplified polymorphism (SRAP) markers to select a mini-core set from 453 sesame accessions in China's germplasm collection. Most previous work 
Table 6. Means, SE, and CV for the quantitative morphological traits for the 106 USDA accessions (acc) and each core set. No differences between means of the entire set and each core were detected by Student's $t$ test $(p<0.05)$.

\begin{tabular}{|c|c|c|c|c|c|c|c|c|}
\hline \multirow[b]{2}{*}{ Trait } & \multicolumn{2}{|c|}{ All USDA acc } & \multicolumn{2}{|c|}{ A-Core ${ }^{\dagger}$} & \multicolumn{2}{|c|}{ M-Core } & \multicolumn{2}{|c|}{ A\&M-Core } \\
\hline & Mean \pm SE & $\mathrm{CV}$ & Mean \pm SE & CV & Mean \pm SE & CV & Mean \pm SE & CV \\
\hline & & $\%$ & & $\%$ & & $\%$ & & $\%$ \\
\hline Plant height, $\mathrm{cm}$ & $103.1 \pm 1.3$ & 13.4 & $105.7 \pm 4.3$ & 13.6 & $104.1 \pm 4.9$ & 17.6 & $106.2 \pm 3.8$ & 16.0 \\
\hline No. primary branches & $3.7 \pm 0.1$ & 15.9 & $3.9 \pm 0.2$ & 14.9 & $3.7 \pm 0.2$ & 20.9 & $3.7 \pm 0.1$ & 16.0 \\
\hline D. to flower initiation & $35.6 \pm 0.3$ & 9.8 & $37.2 \pm 1.4$ & 12.1 & $36.5 \pm 1.2$ & 11.9 & $36.6 \pm 0.9$ & 11.5 \\
\hline D. to $50 \%$ flowering & $39.2 \pm 0.4$ & 9.5 & $40.4 \pm 1.2$ & 10.1 & $40.6 \pm 1.2$ & 10.7 & $40.9 \pm 1.0$ & 10.6 \\
\hline Dist. first capsule, cm & $36.6 \pm 0.7$ & 19.3 & $37.6 \pm 2.7$ & 23.9 & $38.7 \pm 2.1$ & 20.0 & $37.6 \pm 1.8$ & 21.3 \\
\hline No. capsules per plant & $79.8 \pm 2.3$ & 29.4 & $87.8 \pm 7.9$ & 29.7 & $85.1 \pm 12.0$ & 52.9 & $91.4 \pm 8.7$ & 42.8 \\
\hline No. seeds per capsule & $64.5 \pm 1.6$ & 25.6 & $66.2 \pm 4.5$ & 22.5 & $63.2 \pm 4.1$ & 26.5 & $67.3 \pm 3.1$ & 21.5 \\
\hline 1000-seed weight, g & $2.9 \pm 0.04$ & 14.0 & $3.0 \pm 0.1$ & 11.4 & $2.8 \pm 0.2$ & 17.5 & $2.9 \pm 0.1$ & 17.1 \\
\hline Seed yield, $\mathrm{kg} \mathrm{ha}^{-1}$ & $278.1 \pm 8.2$ & 30.4 & $222.7 \pm 23$ & 34.5 & $260.0 \pm 27$ & 43.0 & $261.9 \pm 20$ & 35.9 \\
\hline
\end{tabular}

${ }^{\dagger}$ A-core, amplified fragment length polymorphism; M-core, morphological traits; A\&M-core, both amplified fragment length polymorphism and morphological traits.

has used only morphological traits to select sesame core sets from Chinese (Hodgkin et al., 1999; Xiurong et al., 2000), Indian (Hodgkin et al., 1999), Korean (Kang et al., 2006), and world sesame germplasm collections (Mahajan et al., 2007; Yol and Uzun, 2012). In addition, one study used only molecular markers to select a core set of Chinese sesame germplasm (Zhang et al., 2010). Thus, our work stresses the importance of using both morphological and molecular criteria for selection of germplasm core collections. Such collections hold the most promise for enhancing breeding efforts and preservation of diversity.

\section{Supplemental Materials}

A table of accessions with pedigree numbers and collection locations is included. A map showing the distribution of accessions in Turkey is also included.

\section{Acknowledgments}

This study was supported by grant 1080478 from the Scientific and Technological Research Council of Turkey. We are grateful to the USDA Plant Genetic Resources Conservation Unit, Griffin, GA; and AARI, Menemen, Izmir, Turkey for providing seed samples. Thanks to Amy Frary for a critical review of the manuscript.

\section{References}

Abdellatef, E., R. Sirelkhatem, M.M. Ahmed, K.H. Radwan, and M.M. Khalafalla. 2008. Study of genetic diversity in Sudanese sesame (Sesamum indicum L.) germplasm using random amplified polymorphic DNA (RAPD) markers. Afr. J. Biotechnol. 7:4423-4427.

Ali, G.M. 2007. Assessment of genetic diversity in sesame (Sesamum indicum L.) detected by amplified fragment length polymorphism markers. Electron. J. Biotechnol. 10: 12-17. doi:10.2225/ vol10-issue1-fulltext-16

Amme, S., T. Rutten, M. Melzer, G. Sonsmann, J.P.C. Vissers, B. Schlesier, and H.P. Mock. 2005. A proteome approach defines protective functions of tobacco leaf trichomes. Proteomics 5:2508-2518. doi:10.1002/pmic.200401274

Ashri, A. 1998. Sesame breeding. Plant Breed. Rev. 16:179-228.
Baydar, H. 2005. Breeding for the improvement of the ideal plant type of sesame. Plant Breed. 124:263-267. doi:10.1111/j.1439_ 0523.2005.01080.x

Bedigian, D. 2003. Evolution of sesame revisited: Domestication, diversity and prospects. Genet. Resour. Crop Evol. 50:779-787. doi:10.1023/A:1025029903549

Bedigian, D. 2004. Slimy leaves and oily seeds: Distribution and use of wild relatives of sesame in Africa. Econ. Bot. 58:S3-S33. doi:10.1663/0013-0001(2004)58[S3:SLAOSD]2.0.CO;2

Bedigian, D., C.A. Smyth, and J.R. Harlan. 1986. Patterns of morphological variation in Sesamum indicum. Econ. Bot. 40:353365. doi:10.1007/BF02858991

Bisht, I.S., R.K. Mahajan, T.R. Loknothan, and R.C. Agrawal. 1998. Diversity in Indian sesame collection and stratification of germplasm accessions in different diversity groups. Genet. Resour. Crop Evol. 45:325-335. doi:10.1023/A:1008652420477

Budowski, P., and K.S. Markley. 1951. The chemical and physiological properties of sesame oil. Chem. Rev. 48:125-151. doi:10.1021/cr60149a005

Cagirgan, M.I. 2006. Selection and morphological characterization of induced determinant mutants in sesame. Field Crops Res. 96:19-24. doi:10.1016/j.fcr.2005.06.010

Cho, Y.I., J.H. Park, C.W. Lee, W.H. Ra, J.W. Chung, J.R. Lee et al. 2011. Evaluation of the genetic diversity and population structure of sesame (Sesamum indicum L.) using microsatellite markers. Genes Genomics. 33:187-195. doi:10.1007/s13258010-0130-6

Costa, F.T., S.M. Neto, C. Bloch, and O.L. Franco. 2007. Susceptibility of human pathogenic bacteria to antimicrobial peptides from sesame kernels. Curr. Microbiol. 55:162-166. doi:10.1007/ s00284-007-0131-0

Dixit, A., M.H. Jin, J.W. Chung, J.W. Yu, H.K. Chung, K.H. Ma, Y.J. Park, and E.G. Cho. 2005. Development of polymorphic microsatellite markers in sesame (Sesamum indicum L.). Mol. Ecol. Notes 5:736-738. doi:10.1111/j.1471-8286.2005.01048.x

Earl, D.A., and B.M. Von Holt. 2012. Structure Harvester: A website and program for visualizing structure output and implementing the Evanno method. Conserv. Genet. Resour. 4:359361. doi:10.1007/s12686-011-9548-7

Faostat. 2012. Production statistics. Food and Agric. Organization of the United Nations. http://faostat.fao.org/site/567/default. aspx\#ancor (accessed 5 Nov. 2013). 
Furat, S., and B. Uzun. 2010. The use of agro-morphological characters for the assessment of genetic diversity in sesame (Sesamum indicum L.). Plant Omics J. 3:85-91.

Gaikwad, K.B., J.P. Lal, and R.L. Bhakre. 2009. Combining ability and heterosis for seed yield and related traits in sesame (Sesamum indicum L.). Ann. Plant Physiol. 23:57-61.

Hodgkin, T., G. Qingyuan, Z. Xiurong, Z. Yingzhong, F. Xiangyun, P.L. Gautam et al. 1999. Developing sesame core collections in China and India. In: R.C. Johnson and T. Hodgkin, editors, Core collections for today and tomorrow. CSA/ IPGRI, Rome, Italy. p. 75-81.

Hymowitz, T. 1990. Dedication: Jack R. Harlan crop evolutionist, scholar. In: J. Janick, editor, Plant breeding reviews. Vol. 8. John Wiley \& Sons, Hoboken NJ.

IPGRI and NBPGR. 2004. Descriptors for sesame (Sesamum spp.). IPGRI, Rome, Italy, and NBPGR, New Delhi, India.

Kang, C.W., S.Y. Kim, S.W. Lee, P.N. Mathur, T. Hodgkin, M.D. Zhou, and J.R. Lee. 2006. Selection of a core collection of Korean sesame germplasm by a stepwise clustering method. Breed. Sci. 56:85-91. doi:10.1270/jsbbs.56.85

Kang, C.W., J.I. Lee, and E.R. Son. 1984. Studies on the flowering and maturity in sesame: II. Capsule setting habit by different plant types. Kor. J. Crop Sci. 29:376-385.

Kessler, A., and I.T. Baldwin. 2002. Plant responses to insect herbivory: The emerging molecular analysis. Annu. Rev. Plant Biol. 53:299-328. doi:10.1146/annurev.arplant.53.100301.135207

Kim, K.W., H.K. Chung, G.T. Cho, K.H. Ma, D. Chandrabalan, J.G. Gwag et al2007. PowerCore: A program applying the advanced M strategy with a heuristic search for establishing allele mining sets. Bioinformatics 23:2155-2162. doi:10.1093/ bioinformatics/btm 313

Laurentin, H.E. 2007. Genetic diversity in sesame (Sesamum indicum L.): Molecular markers, metabolic profiles and effect of plant extracts on soil-borne pathogenic fungi. Ph.D. diss., Gottingen Univ., Germany.

Laurentin, H.E., and P. Karlovsky. 2006. Genetic relationship and diversity in a sesame (Sesamum indicum L.) germplasm collection using amplified fragment length polymorphism (AFLP). BMC Genet. 7:10. doi:10.1186/1471-2156-7-10

Laurentin, H.E., A. Ratzinger, and P. Karlovsky. 2008. Relationship between metabolic and genomic diversity in sesame (Sesamum indicum L.). BMC Genomics 9:250. doi:10.1186/1471-2164-9-250

Lee, J.I., C.W. Kang, S.T. Lee, and E.R. Son. 1984. Studies on the flowering and maturity in sesame: I. Flowering habit by different plant types. Kor. J. Crop Sci. 29:76-83.

Mahajan, R.K., I.S. Bisht, and B.S. Dhillon. 2007. Establishment of a core collection of world sesame (Sesamum indicum L.) germplasm accessions. Sabrao J. Breed. Genet. 39:53-64.

Mohamed, H.M., and I.I. Awatif. 1998. The use of sesame oil unsaponifiable matter as a natural antioxidant. Food Chem. 62:269276. doi:10.1016/S0308-8146(97)00193-3

Morris, J.B. 2009. Characterization of sesame (Sesamum indicum L.) germplasm regenerated in Georgia, USA. Genet. Resour. Crop Evol. 56:925-936. doi:10.1007/s10722-009-9411-9

Murty, D.S. 1975. Heterosis, combining ability and reciprocal effects for agronomic and chemical characters in sesame. Theor. Appl. Genet. 45:294-299. doi:10.1007/BF00276682

Noguchi, T., K. Ikeda, Y. Sasaki, J. Yamamoto, and Y. Yamori. 2004. Effects of vitamin $\mathrm{E}$ and sesamin on hypertension and cerebral thrombogenesis in stroke-prone spontaneously hypertensive rates. Clin. Exp. Pharmacol. Physiol. 2:24-26. doi:10.1111/j.1440-1681.2004.04103.x
Pathirana, R. 1992. Gamma ray-induced field tolerance to Phytophthora blight in sesame. Plant Breed. 108:314-319. doi:10.1111/j.1439-0523.1992.tb00136.x

Perrier, X., and J.P. Jacquemoud-Collet. 2006. DARwin software. CIRAD Agric. Res. for Development. http://darwin.cirad.fr/ darwin.(accessed 1 Sept. 2013).

Pritchard, J.K., M. Stephens, and P. Donnelly. 2000. Inference of population structure using multilocus genotype data. Genetics 155:945-959.

Sankar, D., G. Sambandam, M.R. Rao, and K.V. Pugalendia. 2005. Modulation of blood pressure, lipid profiles and redox status in hypertensive patients taking different edible oils. Clin. Chim. Acta 355:97-104. doi:10.1016/j.cccn.2004.12.009

Sensoy, S., M. Demircan, Y. Ulupinar, and I. Balta. 2008. Climate of Turkey. Turkish State Meteorological Serv. www.mgm.gov. tr/files/en-US/climateofturkey.pdf (accessed 2 Apr. 2014).

Tian, D., J. Tooker, M. Peiffer, S.H. Chung, and G.W. Felton. 2012. Role of trichomes in defense against herbivores: Comparison of herbivore response to woolly and hairless trichome mutants of tomato (Solanum lycopersicum). Planta 236:1053-1066. doi:10.1007/s00425-012-1651-9

Uzun, B., and M.I. Cagirgan. 2006. Comparison if determinate and indeterminate lines of sesame for agronomic traits. Field Crops Res. 96:13-18. doi:10.1016/j.fcr.2005.04.017

Wei, L., H. Zhang, Y. Zheng, W. Guo, and T. Zhang. 2008. Developing EST-derived microsatellites in sesame (Sesamum indicum L.). Acta Agron. Sin. 12:77-84.

Wei, W., X. Qi, L. Wang, Y. Zhang, W. Hua, D. Li, H. Lv, and Z. Zhang. 2011. Characterization of the sesame (Sesamum indicum L.) global transcriptome using Illumina paired-end sequencing and development of EST-SSR markers. BMC Genomics 12:451. doi:10.1186/1471-2164-12-451

Weiss, E.A. 1983. Sesame In: E.A. Weiss, editor, Oilseed crops. Longman Inc., New York. p. 282-340.

Xiurong, Z., Z. Yingzhong, C. Yong, F. Xiangyun, G. Qingyuan, Z. Mingde, and T. Hodgkin. 2000. Establishment of sesame germplasm core collection in China. Genet. Resour. Crop Evol. 47:273-279. doi:10.1023/A:1008767307675

Yol, E., and B. Uzun. 2012. Geographical patterns of sesame accessions grown under Mediterranean environmental conditions and establishment of a core collection. Crop Sci. 52:2206-2214. doi:10.2135/cropsci2011.07.0355

Zhang, H., L. Wei, H. Miao, T. Zhang, and C. Wang. 2012a. Development and validation of genic-SSR markers in sesame by RNAseq. BMC Genomics 13:316. doi:10.1186/1471-2164-13-316

Zhang, Y., X. Zhang, Z. Che, L. Wang, W. Wei, and D. Li. 2012b. Genetic diversity assessment of sesame core collection in China by phenotype and molecular markers and extraction of a mini-core collection. BMC Genet. 13:102. doi:10.1186/1471-2156-13-102

Zhang, Y.X., X.R. Zhang, W. Hua, L.H. Wang, and Z. Che. 2010. Analysis of genetic diversity among indigenous landraces from sesame (Sesamum indicum L.) core collections in China as revealed by SRAP and SSR markers. Gen. Genom. 32:207215. doi:10.1007/s13258-009-0888-6 